\title{
Legislação e percepção de professores: gênero na escola
}

\author{
Legislation and teachers' perception: gender in schools
}

\section{Legislación y percepción de profesores: género en la escuela}

\author{
Suzana Lopes Salgado Ribeiro ${ }^{1}$ \\ Pedro Henrique Vieira ${ }^{2}$ \\ Mariana Aranha de Souza ${ }^{3}$ \\ Andrea Paula dos Santos Oliveira Kamensky ${ }^{4}$
}

\section{RESUMO}

As questões de identidade e diversidade de gênero estão presentes na escola. 0 presente artigo apresenta a análise de alguns fatores que compõe a compreensão dessas questões, de acordo com entrevistas realizadas com docentes dos anos finais do ensino fundamental, de uma escola pública, de uma cidade do interior do estado de São Paulo. A pesquisa envolveu também o levantamento da legislação a respeito da regulamentação desta questão nas escolas e se apoiou em referenciais teóricos da área. 0 texto demonstra o desconhecimento dos professores sobre a legislação, sobre estudos produzidos e sobre como trabalhar as questões no ambiente escolar, apontando a necessidade das redes se responsabilizarem por fornecer formações para esses professores para o trabalho com tais questões e assim se efetive uma educação democrática e humana que prepare todos para o convívio com as diferenças.

\section{PALAVRAS-CHAVE}

Gênero. Narrativa. Política Pública. Direito. Educação Básica.

\footnotetext{
${ }^{1}$ Professora do Programa de Pós-Graduação em Educação da Universidade Federal do Mato Grosso do Sul - PPGEDU/UFMS. É pesquisadora do Núcleo de Estudos em História Oral (NEHO/USP), pesquisadora do Centro Simão Mathias de Estudos em História da Ciência (CESIMA/PUC-SP). ORCID: https://orcid.org/0000-0002-0310-0694.

${ }^{2}$ Mestre em Educação pelo Programa de Mestrado Profissional da Universidade de Taubaté - MPE-UNITAU. Professor de História da rede de ensino municipal de Aparecida/SP e Diretor de Escola Pública Estadual (SEDUC/SP). ORCID: http://orcid. org/0000-0003-4010-9003.

${ }^{3}$ Professora do Programa do Mestrado Profissional em Educação da Universidade de Taubaté - Unitau e do Programa PósGraduação em Gestão e Desenvolvimento Regional - PPGDR, Centro Universitário do Sul de Minas - UNIS, ORCID: http://orcid. org/0000-0002-2229-0630.

${ }^{4}$ Professora da Universidade Federal do ABC e Coordenadora do Curso Gênero e Diversidade na Escola - GDE/UFABC. ORCID: http://orcid.org/0000-0002-5394-8415.
} 


\section{ABSTRACT}

Identity and gender diversity issues are present in the school. This article presents the analysis of some factors that make up the comprehension of these questions, according to interviews with teachers of the final years of elementary school, from a public school, from a city in the interior of the state of São Paulo. The research also involved the survey of legislation regarding the regulation of this issue in schools and was based on theoretical references in the area. The text demonstrates the teachers' lack of knowledge about the legislation and how to work the issues in the school environment, pointing out the need for the networks to be responsible for providing training for these teachers to work with such issues that are present in the school daily life.

\section{KEYWORDS}

Gender. Narrative. Public policy. Right. Basic education.

\section{RESUMEN}

Los problemas de identidad y diversidad de género están presentes en la escuela. Este artículo presenta el análisis de algunos factores que componen la comprensión de estas preguntas, según entrevistas con maestros de los últimos años de la escuela primaria, de una escuela pública, de una ciudad del interior del estado de São Paulo. La investigación también incluyó la encuesta de legislación sobre la regulación de este tema en las escuelas y se basó en referencias teóricas en el área. El texto demuestra la falta de conocimiento de los maestros sobre la legislación y sobre cómo trabajar los problemas en el entorno escolar, señalando la necesidad de que las redes sean responsables de proporcionar capacitación para que estos maestros trabajen con tales problemas y, por lo tanto, una educación democrática y humana que prepara a todos para vivir con las diferencias.

\section{PALABRAS-CLAVE}

Género. Narrativa. Política pública. Derecho. Educación básica. 


\section{INTRODUÇÃo}

A escrita do presente artigo decorre de diálogos entre dados coletados a partir da pesquisa que teve como objetivo analisar as narrativas dos professores sobre concepções e práticas que envolvem a abordagem das questões de identidade e diversidade de gênero. Desta forma, o texto abordará três aspectos que envolvem esta temática no cotidiano escolar, a fim de corroborar com as discussões que surgiram em torno da questão, contemporaneamente. Os três aspectos podem ser vistos frente as discussões: da legislação e das políticas públicas para a área; de debates teóricos sobre gênero; e identidade na diferença e da percepção dos profissionais sobre o assunto.

A pesquisa entrevistou seis professores, efetivos de uma escola pública urbana de ensino fundamental (ciclo II), de um município do interior do estado de São Paulo, da região do Vale do Paraíba. Os registros das entrevistas foram conduzidos tendo como norteador metodológico a história oral temática. A partir da gravação em áudio, as entrevistas foram transcritas e conferidas com os professores, de maneira que compreendemos o processo da produção de um documento, oriundo da oralidade:

Uma das contribuições fundamentais que a História Oral trouxe para o atual debate sobre o uso de entrevistas como fonte remete ao sentido do documento e da análise procedida em cima dos textos estabelecidos a partir depoimentos (MEIHY e RIBEIRO, 2011, p. 52).

Esse trabalho foi desenvolvido por meio de pesquisa qualitativa e que teve intensões de compreender o ambiente escolar como um todo complexo e interdisciplinar. Sendo assim entrevistamos professores de diferentes componentes curriculares: Língua Portuguesa, Geografia, História, Ciências e Matemática - tendo como foco o próprio cotidiano escolar, construindo, assim, um panorama das relações de identidade e gênero, por meio da análise das entrevistas realizadas. Os entrevistados foram convidados e explicados sobre os objetivos da pesquisa e as condições de sua partici- pação de forma anônima. Ao aceitarem, assinaram o Termo de Consentimento Livre Esclarecido e suas entrevistas foram gravadas em áudio. Todo o processo de coleta de dados se deu após a aprovação do Comitê de Ética em Pesquisa da Universidade de Taubaté, conforme preconiza a Resolução 510/16 do Conselho Nacional de Saúde.

Desta maneira, os pesquisadores procuraram investigar, por meio da fala dos entrevistados, como são tratadas as questões de gênero e identidade no contexto escolar, tendo como parâmetro a visão docente. Neste processo, compreendem que esses profissionais são os que mais tempo permanecem com os alunos na escola e que suas concepções a respeito dessas temáticas podem contribuir para alargar os horizontes de discussão. Além disso, falar diretamente com professores e registrar suas percepções também foi compreendido como um ato de resistência, como forma de valorização da docência e da educação. Contrapondo-se a certos movimentos que vivenciamos no presente que descartam os saberes dos professores, e para além do discurso, pouco valorizam o que ocorre dentro das escolas.

Além da documentação gerada pelo registro das narrativas, foi feito também o levantamento da legislação e das políticas públicas referentes ao tema. Assim, a partir do material produzido nas entrevistas, buscou-se refletir sobre as concepções à luz dos teóricos contemporâneos que já produziram estudos sobre esses assuntos, bem como da legislação existente, que visa amparar sistemas de ensino, escolas e profissionais que nela atuam, a fim de garantir o princípio da igualdade de tratamento dentro da escola, independente da orientação sexual de cada um.

Também foram levantadas algumas questões referentes à interferência de atitudes discriminatórias e preconceituosas na inserção dos alunos na escola e como estas questões prejudicam a vida escolar dessas crianças e adolescentes, tendo repercussões no ambiente familiar, social e no rendimento escolar.

Desta maneira, a leitura do texto que segue pode contribuir para orientar o trabalho com as questões de gênero, para os que atuam nos mais 
diferentes ambientes escolares visando uma educação para a humanidade e com base nos Direitos Humanos. De modo que, tais questões não se constituam em barreira para o aprendizado e para a convivência, mas possam ser exploradas em toda a sua riqueza, tal como as de natureza étnica, religiosa ou cultural. Podendo contribuir para que a escola se edifique como um ambiente plural e aberto aos mais diferentes constructos sociais e, assim, se torne referência para uma educação verdadeiramente democrática.

\section{IDENTIDADE, GÊNERO E SEXUALIDADE}

Para que seja possível termos um ponto de partida, principalmente em relação aos conceitos apresentados neste texto, trazemos a explicação de gênero formulada por Judith Butler (2003, p. 26) que aponta que gênero se refere à identidade, a forma como uma pessoa se identifica ou se autodetermina. Esta definição está relacionada ao papel que cada pessoa tem na somaneira, "não a biologia, mas a cultura se torna o destino" (Butler, 2003, p. 26), isso porque a identidade é um fenômeno social e não biológico. Assim, gênero é compreendida como categoria identitária cultural de cada sujeito e não definição biológica, mais que isso:

Gênero é o mecanismo pelo qual as noções de masculino e feminino são produzidas e naturalizadas, mas gênero pode muito bem ser o aparato através do qual esses termos podem ser desconstruídos e naturalizados. Um discurso restritivo sobre gênero que insista no binarismo homem e mulher como a maneira exclusiva de entender o campo do gênero atua no sentido de efetuar uma operação reguladora de poder, que neutraliza a instância hegemônica e exclui a possibilidade de pensar sua disrupção. (BUTLER, 2014, p. 253-254).

Partindo dessa premissa, não podemos incorrer no erro de basear a discussão sobre gênero, numa visão simplista de um binarismo - homem e mulher - estático, desconectado das relações so-

cioculturais. Mais do que a simples definição de masculino ou feminino, deve-se, contudo, considerar as definições de gênero à luz do comportamento social dos indivíduos.

Nesse contexto, as questões de gênero precisam ainda, ser observadas sob o seguinte aspecto:

A característica fundamentalmente social e relacional do conceito não deve, no entanto, levar a pensá-lo como se referindo à construção de papéis masculinos e femininos. Papéis seriam, basicamente, padrões ou regras arbitrárias que uma sociedade estabelece para seus membros e que definem seus comportamentos, suas roupas, seus modos de se relacionar ou de se portar. (LOURO, 2003, p. 23-24).

Inserido no contexto social de papeis estabelecidos, há que se considerar ainda as relações de poder existentes.

\begin{abstract}
Homens e mulheres certamente não são construídos apenas através de mecanismos de repressão ou censura, eles e elas se fazem, também, através de práticas e relações que instituem gestos, modos de ser e de estar no mundo, formas de falar e de agir, condutas e posturas apropriadas (e, usualmente, diversas). Os gêneros se produzem, portanto, nas e pelas relações de poder. (LOURO, 2003, p. 41).
\end{abstract}

Nota-se, portanto, que a questão de gênero é complexa frente a (re)existência de padrões ou normatizações impostas socialmente, pois marcam as relações de poder e controle sobre os indivíduos. A dificuldade em conduzir uma abordagem sobre o assunto, em especial no ambiente escolar, apresenta-se, justamente, na ruptura de construção de papeis sociais e de determinismos pré-estabelecidos. 0 que pode entrar em choque com padrões de escola e de sociedade presentes no universo escolar. Ou seja, entendemos que esta disrupção é desafio para os sujeitos escolares envolvidos em manter a ordem.

Esta questão pode ser vista na fala abaixo e mais a frente, quando analisadas as falas dos demais professores: 
Eu nunca entrei no assunto assim com os alunos porque, por ser uma escola dentro de uma cidade católica, isso ainda não é tão debatido em casa pelos pais. Alguns pais aceitam, outros não, porque os alunos já me falaram quando a gente entrou nessa coisa do bullying no começo do ano, os alunos chegaram a comentar sobre isso (Entrevistada " $B$ ").

O que se observou durante o trabalho de campo da pesquisa, é que tanto em casa como na escola o assunto não vem sendo trabalhado e que mesmo frente aos comentários dos alunos o tema não ganha centralidade nas discussões escolares. $\mathrm{Ou}$ seja, a escola resiste.

Frente a este quadro, o que se defende é a necessidade em se pensar gênero dentro do ambiente escolar, e que o conceito seja trabalhado como algo dinâmico, constituído de variáveis sociais, culturais e históricas, no qual o indivíduo possa se perceber um ser plural. Em especial, frente aos embates atuais da supressão de Políticas Educacionais para a área. Assim, a proposta é se pensar uma educação para todos e para o exercício democrático de viver em sociedade entre diferentes, e que a escola seja local seguro para a vivência de crianças e jovens, realizando uma inclusão de fato, nestes tempos de disputas discursivas e crise.

Acrescenta-se a essa discussão a questão da sexualidade, que segundo Guacira Lopes Louro (2003, p.18), assim como a identificação dos sujeitos com um ou outro gênero, também é um processo social e histórico de construção de identidades. A autora não propõe a negação da concepção biológica de corpos sexuados, mas enfatiza que, sobre ela, são exercidas as concepções socioculturais produzidas ao longo do tempo. 0 que propõe com essa discussão é compreender: de que forma as características sexuais são apresentadas a determinada sociedade em um dado momento histórico; de que forma essas características são determinantes nas questões de gênero; e o quanto esse fator limita as individualidades.

Ainda sobre o conceito de gênero, Louro nos apresenta a estreita relação entre identidade e gênero:

\begin{abstract}
A pretensão é, então, entender o gênero como constituinte da identidade dos sujeitos. E aqui nos vemos frente a outro conceito complexo, que pode ser formulado a partir de diferentes perspectivas: o conceito de identidade [...] Ao afirmar que o gênero institui a identidade do sujeito (assim como a etnia, a classe, ou a nacionalidade, por exemplo) pretende-se referir, portanto, a algo que transcende o mero desempenho de papéis, a idéia é perceber o gênero fazendo parte do sujeito, constituindo-o. (LOURO, 2003, p. 24-25).
\end{abstract}

A autora nos apresenta, então, uma abordagem ainda mais ampla, pois estabelece que o gênero seja parte indissociável da identidade dos indivíduos e neste sentido surge a oportunidade de pensarmos um pouco mais sobre a construção social das identidades. Bauman (2005a, p. 46) esclarece que os indivíduos que não se reconhecem nos padrões pré-existentes na sociedade, acabam numa espécie de subclasse social e que, estes vivem o dilema antagônico, entre o reconhecimento e a exclusão, em constante deslocamento, ansiedade, opressão e medo. São marginalizados, implicando num processo de anulação de identidade. Portanto, aquilo que é exigido socialmente aos indivíduos é que se ajustem aos padrões.

Se conjugarmos as ideias de Louro a respeito de gênero estar intrinsecamente ligado ao conceito de identidade, às ideias de Zygmunt Bauman (2005a e 2005b) sobre a marginalização do diferente, vislumbramos a complexidade da temática, principalmente em relação à abordagem de identidade de gênero na comunidade escolar.

\section{LEGISLAÇÃO E POLÍTICAS PÚBLICAS}

Um dos propósitos desse trabalho é demonstrar a existência de legislação que protege os direitos das pessoas de diferentes identidades de gênero. Sobretudo quando o exercício desse direito se dá no âmbito escolar, alvo de análise desse artigo. Para além de listar essa legislação, gostaríamos de destacar que ele está em vigência, e que embora documentos mais recentes como a Base Nacional Comum Curricular - BNCC (Resolução CNE/CP № 2, de 22 de dezembro de 2017), 
silenciem sobre essa temática, há muitos documentos oficiais que podem dar base para o fazer de professores interessados.

Com a perspectiva de fazer um histórico podemos pontuar que no ano 2000, a Assembleia Legislativa do Estado de São Paulo aprovou o projeto de lei no 667/2000, de autoria do deputado Renato Simões. Este se tornou a Lei no 10.948/2001, que dispõe sobre as penalidades aplicáveis à prática de discriminação em razão de orientação sexual. 0 texto da lei, contudo, não abordava, em nenhum de seus artigos, especificamente, o que fazer quando essa discriminação ocorrer em ambiente escolar, mas já marcava um início das balizas para trabalhar a questão dentro das escolas no estado.

Em termos nacionais, um marco pode ser referenciado com a sanção da Lei no 11.340 , de 07 de agosto de 2006. Popularmente conhecida como "Lei Maria da Penha", a lei estabeleceu a criação dos juizados de violência doméstica e familiar contra a mulher e alteração do Código de Processo Penal e Lei de Execução Penal. E dessa forma, criou mecanismos, para coibir e punir a violência doméstica e familiar contra a mulher. Esta pode parecer questão descolada da vivência do cotidiano escolar, entretanto, é preciso pensar o efeito moral e ético que a aprovação de uma lei que criminaliza a violência e coloca no centro do debate o feminino e seus modelos de ser e estar no mundo. Assim, a "Lei Maria da Penha" não regulamenta o ambiente escolar, mas pode e deve adentrar a seus portões. Entendendo que tais relações entre o feminino e o masculino, crivadas pela violência, circundam o universo de vivência de professores e alunos.

Entretanto, mesmo sabendo que essas questões se impõem da vida cotidiana para a escola, e que fica cada vez mais difícil dentro das escolas cegar para tais discussões, quando questionados sobre a temática de identidade de gênero no cotidiano escolar, um dos entrevistados afirmou:

Olha, como isso é o que está surgindo agora para gente de uma maneira diferente do que era antes, eu sei pouco sobre identidade de gênero. Já li alguma coisa, mas, definitivamente, não peguei nada para estudar a respeito (Entrevistado " $B$ ").
A fala do professor aponta a falta de políticas públicas direcionadas para estabelecer espaços de conversas, reflexão e trocas de saberes entre professores, ou mesmo de formação do profissional docente, orientadas para o acolhimento, diálogo e entendimento da questão de diversidade de gênero nos bancos escolares. De modo que esses profissionais não conseguem enfrentar a desconstrução dos padrões socialmente construídos, nem ao menos no binarismo feminino e masculino. Percebemos que, ao longo das entrevistas, a desinformação a respeito de legislação específica, bem como, qual deveria ser o efetivo tratamento dispensado às pessoas de diferentes identidades de gênero, representa quase a totalidade dos profissionais envolvidos. Esta situação se agrava ao entendermos esses sujeitos como educadores e personagens fundamentais das relações estabelecidas com os alunos no processo de ensino e de aprendizagem.

A necessidade da manutenção e ampliação de políticas públicas, principalmente aquelas voltadas aos profissionais de educação, atendo-se ao recorte deste artigo, encontra amparo na resolução no 17, aprovada em 2011, no Conselho de Direitos Humanos da Organização das Nações Unidas. Este dispositivo trata da promoção universal da igualdade, sobretudo relacionado às questões de gênero, sem distinções com base na orientação sexual dos indivíduos. Tal resolução apresenta-se como um importante marco mundial na busca da equidade no reconhecimento das diversidades e escolhas individuais.

Outra entrevistada apresentou o seguinte argumento em relação à legislação específica:

A única legislação que eu lembro, assim, é a que trata do nome social: o indivíduo que quiser ser reconhecido por um outro nome; no caso, mulher pelo nome de homem e vice-versa. Essa é a única legislação que eu tenho agora em mente (Entrevistada "A").

A legislação a qual a docente se refere é o Decreto $\mathrm{n}^{\circ}$ 55.588, de 17 de março de 2010, que dispõe sobre o tratamento nominal das pessoas transexuais e travestis nos órgãos públicos do Estado 
de São Paulo. Mas até mesmo essa legislação, pode ser considerada um tanto genérica, pois não faz alusão, em específico, aos discentes, podendo ser interpretada como referindo-se, em exclusivo, aos funcionários e ou cidadãos (maiores de idade, nesse caso) que se utilizam dos serviços públicos oferecidos pelo ente federado em questão.

Em comunhão com o citado decreto, no ano de 2014, temos a Resolução SE no 45 (Secretaria da Educação/São Paulo), de 18 de agosto, motivada pela Deliberação no 125, do Conselho Estadual de Educação que, ao dispor sobre o tratamento nominal das pessoas transexuais e travestis, no âmbito da Secretaria da Educação do Governo do estado de São Paulo, especifica o termo "discente". Assim, essa resolução resolve que:

Artigo 1ํㅡ - As escolas públicas da rede estadual de ensino devem assegurar o respeito aos direitos individuais e coletivos dos alunos, impedindo quaisquer atos atentatórios ou discriminatórios contra transexuais e travestis, no âmbito de sua atuação (Diário Oficial do Estado de São Paulo, Poder Executivo, São Paulo, 19 ago. 2014. Executivo I, Seção I, p. 15).

Ou seja, o art. 1ํ deixa claro que o objetivo é proteger o aluno de discriminações que possam decorrer das diferentes manifestações de orientação sexual ou de identidade de gênero. Pode-se entender, portanto, que a escola deve se constituir como local para resguardar todos que, diariamente a frequentam, e promover a cidadania e a democracia, por meio do convívio cotidiano entre as diferenças. Entendemos também é um dos papeis da escola pública, compreendida neste artigo como importante local de acesso e garantia ao direito à educação de todos. Para além disso, defendemos que a educação para o convívio com grupos específicos e a inclusão destes na escola como sujeitos é questão de justiça social e de direito humano.

Também nas Diretrizes Nacionais para a Educação em Direitos Humanos, o Parecer no 8 do Conselho Nacional de Educação, estabelece os princípios para uma educação pautada nos Direitos Humanos. Este foi o texto-base que motivou a
Resolução no 1, de 30 de maio de 2012 que, no seu art. $3^{\circ}$, diz que:

Artigo 3o - A Educação em Direitos Humanos,
com a finalidade de promover a educação para a
mudança e a transformação social, fundamenta-
-se nos seguintes princípios: I - dignidade huma-
na; II - igualdade de direitos; III - reconhecimen-
to e valorização das diferenças e das diversida-
des; IV - laicidade do Estado; V - democracia na
educação; VI - transversalidade, vivência e glo-
balidade; e VII - sustentabilidade socioambien-
tal (Diário Oficial da União, Poder Executivo,
Brasília, 30 mai. 2012. Executivo I, Seção I, p. 33).

O referido artigo faz, portanto, referência direta à promoção da dignidade humana, à observância da igualdade de direitos e à valorização das diversidades - que aqui podem ser compreendidas como de gênero. A lei estabelece que a escola deve ser ambiente, não apenas de tolerância à diferença, mas de convívio, respeito e aprendizado sobre o significado e a importância das diferenças e diversidades. Ou seja, a escola deve ser ambiente de defesa de direito.

Destacamos, portanto, que mesmo frente a existência de leis que regulamentam a acolhida e valorização da diferença no ambiente escolar, muitos sujeitos inseridos no cotidiano da comunidade estudada alegam ignorância em relação às questões de gênero. Aí reside a importância da defesa das políticas públicas, e das formações continuadas, que possam promover o conhecimento da legislação e o cumprimento das funções das instituições de ensino estabelecidas por lei dentro da dinâmica escolar e em diálogo com a realidade do professor. Neste sentido, como afirma o docente abaixo, após conversa com os pesquisadores sobre a legislação, o contato com estes conhecimentos se constitui como parte integrante do processo de formação contínua:

Realmente, eu ainda desconheço; não sabia nem que existiam essas legislações e, confesso que, a partir de agora, vou procurar parar e pensar um pouco mais e pesquisar, porque acho que isso é formação contínua. Acho que isso éindissociável da área da docência (Entrevistado "C"). 
A fala em questão apresenta dois aspectos fundamentais e inseparáveis: primeiro, a percepção de que a formação docente, não vem ocorrendo ou não foi capaz de abranger a problemática abordada e; segundo, que o professor se percebe como agente de transformação e que, nesse sentido, cabe também a ele, a busca de informação e reflexão que são contínuas na profissão. 0 primeiro aspecto se relaciona com o segundo e frente as complexas condições de trabalho e remuneração enfrentadas pelo professorado, agravam-se as possibilidades de busca individual por formação. Além disso, destaca-se que a educação pública não pode e não deve ficar a cargo da iniciativa particular de um ou outro educador, a formação pode ser em serviço e, portanto, deve ser assumida pelas redes que gerem as escolas, sejam elas municipais, estaduais ou federais.

Diante disso, se essa pluralidade de princípios, expressos na legislação, faz parte de uma educação que preserva e assegura a dignidade da pessoa humana, e estabelece diretrizes para isso. A escola e seus educadores não podem se omitir ou alegar desconhecimento da questão. Entretanto, alguns podem alegar que o conhecimento da legislação que regulamenta o serviço público prestado por um servidor deve ser pensado como parte de suas atribuições profissionais. E isso é verdadeiro. Por um lado, concursos públicos e seleções para os cargos escolares poderiam ter maior preocupação com a cobrança relacionada a esses temas. Mas, por outro lado, na medida em que não cobram e aprovam esses profissionais, ou já têm um contingente de profissionais contratados anteriormente à legislação, passa a ser responsabilidade das próprias redes oferecer possibilidades de atualização para seus educadores, o que não tem sido feito ou tem sido realizado de forma muito tímida.

Dessa forma, muitas vezes, professores por desconhecimentos de seu papel no processo de mediação e desconstrução de preconceitos e estereótipos deixam seus estudantes à mercê de brincadeiras humilhantes, tratamentos vexatórios e desrespeito. Enfim, tais docentes, por vezes, perdem oportunidades de trabalhar as questões do convívio com a diferença e, sobretudo, mostrar que a diversidade compõe a vida humana e assim fazer cumprir a legislação em seu cotidiano escolar.

Perdem a chance, também, de trabalhar com seus alunos a desconstrução de estereótipos discriminatórios e por vezes, mesmo sem querer, reforçam padrões e reproduzem nas atividades cotidianas comportamentos construídos socialmente, naturalizados e invisibilidados no currículo escolar se tornando "fabricante das desigualdades", à medida que ao longo da história separou os sujeitos estabelecendo normas que "produzem diferenças entre as pessoas" (Louro, 2003, p.57). A escola, portanto, quando o professor não recebe a oportunidade de se formar para trabalhar tais temas não se torna o local do acolhimento da pluralidade de formas de se expressar a afetividade e deixa de explorar a multiplicidade de identidades presentes em sua própria comunidade e como essa diversidade pode contribuir para um saber plural, rico em vivências, exigente no tocante ao respeito. Entretanto, o que vemos surgir, é o que foi apresentado por Anna Paula Vencato:

O sistema de ensino que leva em conta essa lógica tenta pasteurizar as diferenças e padronizar os conteúdos e formas de ensinar. Ele aspira dar uma escolarização única a todas as pessoas, ignorando suas especificidades. 0 que ocorre, ao cabo, é que justamente ao desconsiderar as diferenças e padronizar pessoas e conteúdos, a escola perpetua as desigualdades existentes na sociedade. (VENCATO, 2014, p. 39)

Importa também dizer que a escola passa por reformas constantemente, e que seus sujeitos clamam por mudanças e, por isso não pode se omitir em discutir temática tão complexa e importante como identidade de gênero e convívio com a diversidade. Ao contrário disso, espera-se que essa instituição assuma seu papel nesta discussão, de modo que olhares possam ser ampliados e visões pré-concebidas e estereotipadas possam ser desfeitas e que se enfrentem entraves, como o que se percebe no depoimento a seguir:

Mas já ouvi o pessoal comentando na sala dos professores uma coisa relativa a nome social. $O$ assunto me chamou a atenção e entrei na con- 
versa. Foi quando fiquei sabendo, para meu espanto que, seu eu tiver uma aluna de nome Maria, mas que queira ser chamada de José, ela tem esse direito. Dentro da escola, por mim, pelos colegas, pelos funcionários ela tem o direito de ser chamada pelo nome que escolher. Ah, ainda tem outro absurdo: quando ela for se formar e a escola expedir o diploma - ou certificado, sei lá -, o nome que terá que constar é o da Certidão de Nascimento, ou seja, aquele nome pelo qual ela foi chamada na escola durante toda sua vida de estudante, não tem valor naquele momento (Entrevistada " $E$ ").

A colaboradora, em sua fala, parece manifestar certa aceitação em chamar o/a aluno/a pelo nome no gênero com o qual o sujeito estabelece sua identidade. Mesmo assim, é possível apontar a dificuldade em mediar sua linguagem, e o quanto nela se pode transparecer preconceitos. Neste sentido, importa lembrar do ponto de atenção indicado por Louro ao dizer da necessidade de desconfiar do que é imposto como "natural", posto que a desigualdade pode ser naturalizada (Louro, 2003, p. 57).

Mesmo assim, na continuidade da fala da professora, por parecer aceitar esta possibilidade de auto reconhecimento, vê com embaraço que a documentação oficial desse aluno não atenda à condição de sua identidade de gênero, que foi reconhecida anteriormente. A professora, com afirmações por vezes um pouco confusas, denuncia uma contradição do legislador, que parece não ter se preocupado em resolver e que coloca um problema de ordem burocrática à dinâmica de funcionamento da escola.

Embora os documentos orientadores de no 14 e 15 da Coordenadoria de Gestão da Educação Básica (CGEB) de 2014 orientem a questão referente a utilização de nome social em ambiente escolar, sabemos que o que disciplina a burocracia, sobretudo quanto à expedição de documentos é a legislação que, nesse caso, mostrou-se inalterada. Permitindo o chamamento público pelo nome que a pessoa escolher, mas garantindo que a emissão de documentos deve ser feita com base na Certidão de Nascimento.
No ano de 2015, a Nota Técnica $\mathrm{n}$ o 24/2015 da SECADI (Secretaria de Educação Continuada, Alfabetização, Diversidade e Inclusão), do MEC (Ministério da Educação e Cultura), motivou a edição da Resolução no 12/2015, do CNCD/LGBT (Conselho Nacional de Combate à Discriminação e Promoção dos Direitos de Lésbicas, Gays, Travestis e Transexuais), estabelecendo que todas as pessoas tenham sua identidade de gênero reconhecida em diferentes espaços sociais - inclusive instituições de ensino -, com orientações quanto ao reconhecimento da identidade de gênero e sua operacionalização. Importa dizer que a SECADI foi secretaria criada em 2004, como resultado de diálogos com movimentos sociais, e foi extinta no início da gestão do Governo do Presidente Jair Bolsonaro em janeiro de 2019, após o ex-ministro Vélez Rodriguez assumir o MEC - Ministério da Educação e Cultura.

Dito isto, há que se ter claro os instrumentos que marcam as conquistas e que podem auxiliar a trilhar o caminho de uma convivência democrática. Importa dizer que há muito o que avançar, mas que também é preciso defender o que foi estabelecido para que possamos, respaldados por legislações e políticas públicas específicas, estabelecer trajetórias das mobilizações e conquistas assim como projetar caminhos futuros.

\section{FORMAÇÃO PROFISSIONAL E GÊNERO}

Destacamos a importância da formação para que professores possam compor seu repertório para trabalhar as questões de gênero de forma competente nas escolas. E o papel do Estado - seja ele representado por redes públicas municipais ou estaduais - em garantir o acesso a esta formação. Assim, neste item evidenciamos a fala dos professores sobre o assunto que nos mostram o quanto os docentes não se sentem à vontade para tocar nas questões de identidade de gênero com seus alunos, mesmo esta estando presente na sala de aula, no pátio ou em qualquer outro lugar do ambiente escolar. A fala registrada de um de nossos colaboradores mostra que a questão ainda não é enfrentada nem pela escola, nem pela rede de ensino: 
Então, nesses anos agora... [...] 2015 e 2016 -, não tenho percebido, pelo menos, não no Fundamental II, uma movimentação, em nível de rede, ou até mesmo da própria escola, na questão da gestão, para trabalhar especificamente com a questão da discriminação tanto do gênero quanto até do ponto de vista étnico (Entrevistado " $\mathrm{C}$ ").

Evidentemente, pensamos que é função de todo profissional buscar aperfeiçoamento para o exercício de sua função, e isso não é diferente para o professor. Mas não há como desconsiderar a importância da formação continuada, pelo poder público e que, nesse caso, se mostra falha à medida que os professores entrevistados afirmaram que não puderam estudar, no tempo de sua atividade de trabalho, em relação a abordagem de gênero, identidade e sexualidade.

Ou seja, sem um posicionamento mais claro dos gestores educacionais, dificilmente será possível construir um cotidiano escolar sobre bases do convívio democrático com as diferenças e isso se agrava em momentos em que gênero passa, mais que anteriormente, um tema tabu.

Porém, para que a escola seja um espaço democrático, é preciso deixar que as conversas aconteçam e munir o professor de conhecimentos que junto aos seus possam compor práticas de convívio humanizador. Para isso acontecer, todos os profissionais envolvidos com a questão educacional devem ter um olhar amplo e plural, quanto às questões de identidade de gênero que se apresentam, diariamente, na escola. Tais olhares precisam estar distantes de estereótipos, paradigmas de normalidade ou preconceitos. Isso porque, o professor, enquanto educador, por vezes pode não se sentir à vontade ou informado para o trabalho com as questões de gênero e sexualidade - tal como se percebe na fala a seguir:

Acho que a própria escola mesmo, através da Coordenação e Direção poderia propiciar essa formação para gente, através das horas de HTPC. Mas... não sei não, talvez por ser uma questão delicada e uma novidade, tudo junto, ninguém queira tocar no assunto. Mas é uma necessidade, pois a cada ano que passa, recebemos mais alunos homossexuais na escola, tanto meninas, como meni- nos, né? E o pior, tem colega que, como a gente sabe, não toca no assunto porque não tem domínio sobre essa questão. (Entrevistado " $E$ ")

Na fala do entrevistado acima, podemos perceber um pedido de ajuda, demandando por formações dialógicas que possam ser conduzidas no espaço de trabalho e coletivamente. Os professores enfrentam questões cada dia mais complexas de relacionamentos e falta de respeito nas escolas e muitas vezes as próprias estruturas de formação existentes nas escolas - como as horas de trabalho pedagógico coletivo (HTPC) - não elegem como prioridade o desenvolvimento de discussões sobre tais questões. Os termos "delicada" e "novidade" que aparecem na fala do nosso colaborador mostram que, a presença de homossexuais no contexto escolar é algo que por vezes causa estranhamento nos docentes. 0 próprio uso de "novidade" pode ser problematizado. As conquistas dos direitos e a possibilidade social de expressar diferentes identidades de gênero, fazem com que, aquilo que antes era velado, encoberto, mascarado e estigmatizado, hoje se apresente de forma mais evidente no cotidiano.

Talvez "novidade" não seja a presença de alunos homossexuais, mas esta realidade que impõe desafios aos professores que passam a ter que mediar conflitos sem o conhecimento necessário para fazê-lo. 0 professor, que poderia ser um orientador em seu processo de formação identitária e cidadã, passa a não conseguir realizar este trabalho e se frustra, ou nem tenta. E neste movimento, por vezes o assunto vai tomando proporções indesejadas, expressas em atitudes de intolerância, de modo a prejudicar diferentes sujeitos da comunidade escolar.

Lidar com os diferentes corpos assume muitas facetas, que devem ser enfrentadas. Algumas delas não passam pela questão de gênero e sexualidade, mas, ainda assim se tornam questões "delicadas". Pela citação a seguir, percebemos o esforço de uma das entrevistadas nesse sentido:

Primeiro, tem criança que, às vezes, brincando com a outra, simplesmente por causa do corpo, 
acaba soltando "você é gordo", e isso não pode. Ninguém pediu para ser... ou melhor, para ter o que tem, e isso precisa ser trabalhado. Quando é trabalhado no início, isso gera um adolescente equilibrado, um adulto sensato a, quem sabe, respeitar às diferenças (Entrevistado "D").

Mesmo inquerida sobre as temáticas de gênero e identidade, a professora não responde de forma objetiva. Ou seja, resolveu abordar a questão da obesidade, que está relacionada ao corpo e que também é fator de preconceito e discriminação no cotidiano escolar. Mas a fala foi selecionada justamente por isso. A fala transparece a dificuldade do professor em tratar dos assuntos de gênero e sexualidade de forma objetiva, e quando questionado, busca alternativas para não tocar nas questões de identidade decorrentes.

$\mathrm{Na}$ maioria das vezes - conforme se pode observar pelo excerto da entrevista a seguir - o professor acaba colocando a questão de gênero dentro da ampla seara do bullying. Isso se dá talvez por ser esta uma questão mais aceita, embora muitas vezes também pouco trabalhada. Então, seja porque o professor entende que é assim que a questão deve ser abordada, seja porque não quer envolvimento mais próximo numa questão que julga ser de foro íntimo e pessoal. Entretanto, registramos que quando se exime ou mascara a situação, o professor contribui para que a mesma seja superficialmente tocada e/ou tratada à distância.

Contodo, nota-se que esta se tornado uma janela aberta para se trabalhar as questões da diversidade na escola. Como a violência e o desrespeito estão presentes, mas muitos vezes, redes, gestores e professores não querem ou não podem enfrentar de forma direta as questões do preconceito, tem sido desenvolvidos trabalhos como:

O Projeto de Bullying me remete agora ao fato de uma parceria da Prefeitura, na qual há alguns anos atrás. Eu fiquei com um 2o lugar no concurso de paródias, relacionado ao bullying. E isso me inspira bastante; me inspirou até hoje, para poder trabalhar isso em sala de aula. Então, quando eu percebo em sala de aula alguma situação que possa levar ao bullying ou até mesmo à violência exagerada e verbal - eu trabalho textos de cons- cientização, dinâmicas de perfil social, de como o aluno pode se comportar e de como todos somos iguais, dentro da ideia das diferenças, sejam estas culturais, étnicas, sexuais. (Entrevistada "A")

A partir da fala da professora, é possível entender que o trabalho sobre temas como comportamento, alteridade, diferenças, etnia e sexualidade se fazem presentes na escola, mas trabalhados de forma dispersa e não de maneira preventiva, mas como contenção de uma situação estabelecida. Interessante, também perceber que em sua fala, não diz tratar de questões de gênero e, sim, de diferenças sexuais. E gostaríamos de pontuar que a questão de gênero quando abarcada pelo viés do bullying, acaba perdendo a força e a dimensão do direito. Direitos estes conquistados historicamente e emblemados pela luta social de movimentos sociais e populares e, sabemos da dificuldade de se ver esses direitos respeitados. Entretanto, em tempos de crise e de questionamento de direitos são possibilidades de melhorar concretamente o convívio das crianças e jovens.

Outra professora afirmou:

No caso de orientação sexual, eu só falo (abertamente mesmo) sobre a vida sexual, que é para tomar cuidado e, pelas músicas que eles ouvem, de funk, que são letras bastante erotizadas, graves para a idade deles. Eu penso assim, pesadas, embora eles falem normalmente. Então, sobre isso eu falo, sobre ter relação sexual muito cedo, que é para se guardar, mesmo menino e menina, eu trato os dois iguais. Falo do uso da camisinha, que tem que tomar cuidado e que é para eles conversarem com os pais. Mas não a questão de ser gay ou deixar de ser gay. Eu não entro nesse assunto (Entrevistada " $B$ ").

A professora mostra que ao tratar das questões de sexualidade, embora se preocupe com a orientação de seus alunos, não aborda o assunto de maneira "abertamente mesmo", ou seja, transparece na forma como fala que parece sentir que poderia fazer melhor. E essa avaliação já é algo positivo se pensarmos a auto-reflexão do professor sobre sua prática de ensino. Além disso, em suas afirmações é possível verificar certo afastamento de suas per- 
cepções com relação ás músicas que ouvem ou como se comportam seus estudantes.

Entendendo na perspectiva do referencial teórico utilizado por este artigo que os conceitos e que as identidades têm caráter de construção, compreendemos que o processo de formação continuada pode auxiliar este professor que quer trabalhar melhor, mas não sabe como a realizar sua função com maior profissionalismo e competência de modo a não reforçar exclusões dentro do ambiente escolar, transformando assim sua própria identidade docente.

Neste sentido, Bauman discute ao longo das páginas de sua obra (2005b) que as pessoas que vivem em condições de exclusão são consideradas "vidas desperdiçadas". São pessoas rejeitadas, e é essa exclusão que está na base do aprofundamento da polarização social, da miséria, da desigualdade e da humilhação. Vale lembrar que fazem parte deste grupo de excluídos da contemporaneidade tanto os alunos com comportamentos considerados desviantes, quanto os próprios professores, frente a crescente desvalorização de suas carreiras e saberes.

Nesta medida, tais sujeitos - docentes e discentes - podem ser considerados como pertencentes a uma "subclasse", sempre inferiores na hierarquia de poder e seus protestos raramente serão ouvidos. Bauman (2005b, p.68) afirma que a maioria das pessoas "paira" entre o reconhecimento e a exclusão, vivendo em constante deslocamento, ansiedade, opressão e medo. Em um movimento pendular entre reconhecimento e exclusão os professores podem ou não excluir seus educandos no cotidiano escolar simplesmente ao escolher tratar ou não de um assunto como identidade de gênero.

Essa visão interessa particularmente por entender a necessidade da luta por uma educação democrática ser representada por todos os sujeitos da comunidade escolar e perceber que só assim, professores e alunos poderão ser respeitados como sujeitos de seus fazeres. Essa união pode reforçar a luta pelas carreiras docentes, pelo reconhecimento da educação como um direito de todos e valorização da escola pública como um espaço do convívio plural com a diferença.

\section{CONSIDERAÇÕES FINAIS}

Neste artigo percorremos um caminho que tentou aproximar o conhecimento sobre a legislação e sobre a percepção de professores em relação às questões de gênero na escola. Pudemos, a partir de uma cronologia da legislação, defender a necessidade da existência e da defesa do que já foi criado em termos de políticas públicas para a área além de compreender a importância da ampliação da formação para professores sobre a temática. Isso porque, os profissionais que atuam nos diferentes contextos de uma instituição de ensino, como a estudada, devem estar preparados para garantir, a todo público discente, uma educação que garanta os direitos da pessoa humana, respeitando e valorizando a diversidade.

Destaca-se, portanto, na aplicação da legislação, bem como no suporte do exercício profissional, do professor a necessidade de políticas públicas que valorizem o debate sobre as questões das diferenças, e, em especial das diversas identidades de gênero, que segundo os professores estão presentes no cotidiano da escola.

Partindo da defesa dos direitos de se expressar livremente, torna-se injustificável um tratamento preconceituoso e discriminatório estabelecido no ambiente escolar seja no tratamento de educando ou de educadores. Contudo, como de acordo com as entrevistas analisadas, podemos perceber um pedido por formação sobre as questões de gênero, identidade e sexualidade, e compreender que por vezes o desconhecimento da questão incide na reprodução de preconceitos a este respeito.

A partir desse texto, queremos chamar a atenção para todos os envolvidos com a educação, que a abordagem da questão de gênero é urgente. $\mathrm{Ou}$ seja, pode ser silenciada ou encoberta no cotidiano escolar, como no passado, ou como se propõe em nosso momento presente. Mas é preciso ter em mente que isso é uma perda para a vivência democrática - que pressupõe o convívio de todos os cidadãos. E, que representa uma violência contra setores de nossa população que não devem ser marginalizados e que nas últimas décadas puderam se fazer presentes em lutas cotidianas que 
promoveram a discussões e as trouxeram para o espaço público. E têm, por lei, direito a isso.

Nesse cenário, a escola não está e não pode ficar à margem de tais discussões e mudanças vividas no presente. Deve assumir estes debates, pois é palco
- queira ou não - dessas manifestações. Porém, para que isso aconteça, existe a necessidade imediata de profissionais compreendendo seus papeis como formadores prontos para olhar as questões emergentes, efervescentes e contemporâneas. 


\section{REFERÊNCIAS}

BAUMAN, Zygmunt. Identidade. Rio de Janeiro: Jorge Zahar Editor, 2005a.

BAUMAN, Zygmunt. Vidas desperdiçadas. Rio de Janeiro: Jorge Zahar Editor, 2005b.

BRASIL. Constituição da República Federativa do Brasil, de 05 de outubro de 1988. Diário Oficial [da] União. Poder Legislativo, Brasília, DF, 05 out. 2010. Legislativo I, Seção I, p. 1, art. 205.

BRASIL. Secretaria da Justiça e da Defesa da Cidadania. Lei n. 10.948, de 05 de novembro de 2001. Dispõe sobre as penalidades a serem aplicadas à prática de discriminação em razão de orientação sexual. Diário Oficial [do] Estado de São Paulo, Poder Executivo, São Paulo, 06 mai.2014. Executivo I, Seção I, p. 2.

BRASIL. Organização das Nações Unidas. Direitos Humanos. Resolução n. 17, de 17 de junho de 2011. Disponível em: <https://nacoesunidas.org/conselho-de-direitos-humanos-adota-resolucao-sobre-orientacao-sexual-e-identidade-de-genero/> Acesso em: 05 jun. 2016.

BRASIL. Ministério da Educação. Conselho Nacional de Educação. Resolução CNE/CP n. 1, de 30 de maio de 2012. Estabelece Diretrizes Nacionais para a Educação em Direitos Humanos. Diário Oficial [da] União, Poder Executivo, Brasília, 30

BRASIL. Ministério da Justiça e Cidadania. Secretaria Especial de Políticas para as Mulheres. Nota Técnica n. 24, de 17 de agosto de 2015. CGDH/DPEDHUC/SECADI/MEC. Define o conceito de gênero no Plano Nacional de Educação. Disponível em: < http://www.spm.gov.br/assuntos/conselho/nota-tecnica-no-24-conceito-genero-no-pne-mec.pdf > Acesso em: 05 jun. 2016.

BRASIL. Ministério da Justiça e Cidadania. Secretaria Especial de Direitos Humanos da Presidência da República. Cartilha os Direitos Humanos. Disponível em: <http://www.sdh.gov. br/noticias/2016/outubro/secretaria-especial-de-direitos-humanos-lanca-cartilha-de-emendas-2017> Acesso em: 05 mar. 2017.

BUTLER, Judith. Problemas de gênero: feminismo e subversão da identidade. Rio de Janeiro: Civilização Brasileira, 2003. BUTLER, Judith. Regulações de Gênero. Cadernos Pagu, v. 42, n.1, p. 249-274, 2014.

LOURO, Guacira Lopes. Gênero, sexualidade e educação: uma perspectiva pós-estruturalista. 6. ed. Petrópolis: Vozes, 2003.

MEIHY, José Carlos Sabe Bom e RIBEIRO, Suzana Lopes Salgado Ribeiro. Guia prático de História Oral: para empresas, universidades, comunidades, famílias. São Paulo: Contexto: 2011.

SÃo PAULO. Secretaria da Justiça e da Defesa da Cidadania. Lei n. 10.948 , de 05 de novembro de 2001. Dispõe sobre as penalidades a serem aplicadas à prática de discriminação em razão de orientação sexual. Diário Oficial [do] Estado de São Paulo, Poder Executivo, São Paulo, 06 mai.2014. Executivo I, Seção I, p. 2.

SÃO PAULO. Secretaria da Casa Civil. Decreto n. 55588, de 17 de março de 2010. Dispõe sobre o tratamento nominal das pessoas transexuais e travestis nos órgãos públicos do Estado de São Paulo e dá providências correlatas. Diário Oficial [do] Estado de São Paulo, Poder Executivo, São Paulo, 18 mar. 2010. Executivo I, Seção I, p. 8.

SÃo PAULO. Secretaria da Justiça e da Defesa da Cidadania. Decreto n. 55839, de 18 de maio de 2010. Institui o Plano Estadual de Enfrentamento à Homofobia e Promoção da Cidadania LGBT e dá providências correlatas. Diário Oficial [do] Estado de São Paulo, Poder Executivo, São Paulo, 19 mai.2010. Executivo I, Seção I, p. 4.

SÃO PAULO. Secretaria da Educação. Coordenadoria de Gestão da Educação Básica. Documento Orientador n. 14/2014. Diversidades Sexuais e de Gênero. São Paulo. 2014.

SÃO PAULO. Secretaria da Educação. Coordenadoria de Gestão da Educação Básica. Documento Orientador n. 15/2014. Tratamento Nominal de Discentes Travestis e Transexuais. São Paulo. 2014

SÃO PAULO. Secretaria da Educação. Conselho Estadual de Educação. Deliberação n. 125, de 30 de abril de 2014. Dispõe sobre a inclusão de nome social nos registros escolares das instituições públicas e privadas no Sistema de Ensino do Estado de São Paulo e dá outras providências correlatas. Diário Oficial [do] Estado de São Paulo, Poder Executivo, São Paulo, 01 mai.2014 Executivo I, Seção I, p. 34.

SÃO PAULO. Secretaria da Educação. Resolução SE n. 45, de 18 de agosto de 2014. Dispõe sobre o tratamento nominal de discentes transexuais e travestis, no âmbito da Secretaria da Educação. Diário Oficial [do] Estado de São Paulo, Poder Executivo, São Paulo, 19 ago.2014. Executivo I, Seção I, p. 15.

VENCATO, Anna Paula. Diferenças na Escola. In: MISKOLCI Richard, LEITE JR, Jorge. Diferenças na Educação: outros aprendizados.1 ed. São Carlos: EdUFSCar, 2014, p. 19-56. 